\title{
Prevalence and cluster effect of self-reported allergic reactions among insect consumers
}

\author{
Summon Chomchai, ${ }^{1}$ Praphai Laoraksa, ${ }^{2}$ Prich Virojvatanakul, ${ }^{2}$ Parsimone Boonratana, ${ }^{2}$ Chulathida Chomchai ${ }^{2}$
}

\begin{abstract}
Background: Entomophagy is a common practice in many parts of the world. Allergic symptoms after insect consumption have been reported in healthcare literature and in the news.
\end{abstract}

Objectives: We evaluated prevalence and association of allergic history and self-reported allergic reactions after entomophagy.

Methods: We conducted a cross sectional internet-based survey. Participants were people who have consumed insects. Collected information included demographic data, the practice of entomophagy, allergic history and self-reported allergic symptoms.

Results: During May to October 2017, 140 people completed the survey. Median and range of age are 27 and 18-64 years. Ninety-two (65.7\%) were female. Thirty-seven (26.4\%) and $13(9.3 \%)$ participants had history of allergy and seafood allergy, respectively. Eighteen (12.9\%; 95\% confidence intervals (CI) 7.3-18.4) participants reported allergic reactions after insect consumption. Nine symptomatic participants reported other people who partook insects to have allergic symptoms. Reported factors with significant association with allergic reactions were history of allergy and seafood allergy with prevalence ratios of 4.83 (CI 1.83-10.44) and 3.76 (CI 1.59-8.87), respectively.

Conclusion: The prevalence of self-reported allergic reactions after entomophagy is $12.9 \%$. Clusters of people with post-entomophagy allergic symptoms are found. History of allergy and seafood allergy are associated with post-entomophagy allergic reactions.

Key words: Entomophagy, histamine, scombroid, anaphylaxis, silkworm, grasshopper, cricket, bamboo caterpillar

From:

${ }^{1}$ Faculty of Medicine Siriraj Hospital, Mahidol University, Bangkok, Thailand

${ }^{2}$ Mahidol University International College, Mahidol University, Nakhon Pathom, Thailand

\section{Introduction}

Entomophagy is a common practice for cultural, economic, and environmental reasons. ${ }^{1-3}$ While the consumption of silkworm pupae is found among silk-production cultures because the pupae are by-products from silk spooling, grasshoppers caught from herds of migrating locusts in the field, are a naturally-found, seasonal source of protein. Crickets and bamboo caterpillars, on the other hand, are especially farmed for their economical values as specialty food items and are otherwise known as six-legged livestock. ${ }^{2}$ Worldwide, contemporary reasons supporting entomophagy in human are mainly nutritional and sustainability as food security to mankind. Insects contain high protein, minerals and vitamins with relatively low

\section{Corresponding author:}

Chulathida Chomchai

Mahidol University International College, 999 Phutthamonthon 4 Road, Salaya, Nakhon Pathom 73170, Thailand

E-mail: chulathida.cho@mahidol.ac.th fat contents. Production of insects as livestock are more environmentally friendly since it requires significantly less feed, water and space, while emitting less greenhouse gases, as compared with poultry and cattle., ${ }^{2,3}$ However, with entomophagy being on the rise both as small domestic, and large-scale commercial productions, safety cannot be overlooked. ${ }^{3}$

Allergy from insect consumption is reported intermittently in the news in countries where entomophagy are common, for example, in Southeast Asia with symptoms such as urticarial rash, bronchospasm and anaphylaxis. ${ }^{4-7}$ Cases are often isolated and sporadic, occurring in small clusters, with infrequent reports of large scale outbreaks that involve anywhere 
from 27 to 118 patients. ${ }^{1,4-9}$ Considering the scarcity of epidemiologic information, no public awareness has been raised considering the prevalence and risk of allergic symptoms which can occur from insect consumption. ${ }^{1,10}$ And while public health agencies often caution against insect consumption in individuals with allergic illness, there are as yet no scientific evidence to support susceptibility to allergic symptoms among patients with allergic history after consumption of insects. ${ }^{11,12}$ This study aims to assess the prevalence and to fill in the knowledge gap regarding the relationship between underlying allergic disease and the development of allergic symptoms after insect consumption.

\section{Methods \\ Study design}

This was an internet-based cross-sectional survey of people who practiced entomophagy. The study was conducted from May 1, 2017 to October 31, 2017. The survey questions and utilization of data received approval from Siriraj Institutional Review Board (SIRB) prior to study commencement. Recruitment was done through 2 venues. Poster advertisements were placed in and around Bangkok's Khaosan Road area where tourists and backpackers frequently come in contact with several fried insect vendors. Recruitment information was also posted in popular Thai social network websites Pantip (https:// pantip.com/) and KhonkhaenLink (https://www.khonkaenlink. info/) websites. In both settings, potential participants would encounter the first page of the online questionnaire containing an informed consent form and participant information sheet and were asked to leave the survey if they are under 18 years of age.

\section{Subjects}

A history of insect ingestion was the only inclusion criteria. Participants were excluded from the final analysis if they did not specify the type of insect consumed or the symptoms experienced. Targeted sample size for the study was 113 subjects, based on calculated sample size of 94 for chi-square goodnessof-fit tests, $20 \%$ contingency, alpha 0.05 , beta 0.80 and effect size 0.41 (chi-square value 7.06, sample size 42 ). ${ }^{5}$ In addition, sample size for prevalence study was estimated using known prevalence value of $7.6 \%$, precision value of $5 \%$ and confidence level of $95 \%$. The required sample size is 101 cases. $^{1,13}$

\section{Data collection}

Content of the questionnaire was reviewed and commented by allergist and clinical epidemiologists for validity. The online questionnaire was piloted on Windows, iOS and Android operating systems, on personal computers, tablets and smart phones to ensure that it is user-friendly and precise. Participants were told the questionnaire was to assess "any illness or discomfort after insect consumption" and had the choice of questionnaire in either the Thai or English languages. The questionnaire contained 23 items including demographic information, gender, nationality, place of residence, and past medical history, including that of allergic diseases, irritable bowel disease and inflammatory bowel disease, and presence of specific food allergies. Specific details regarding the participant's experience with entomophagy were obtained such as the type of insect ingested, source and form of insect ingested, frequency and reasons of entomophagy. In order to ascertain the occurrence of true allergic reaction to insects and reduce participant bias, a 17-item symptom list was formulated which included both allergy-associated and non-allergy associated symptoms involving the skin, respiratory, gastrointestinal and general symptoms. If participant report having symptoms after insect ingestions, they were asked secondary questions such as if they suspected a specific insect to be the cause, the time lapse between consumption and development of symptom, if they know of other people who consumed the same batch of insects who also developed symptoms and if the participant sought medical attention. No personal identification data was collected in this study.

\section{Classification of symptoms}

Using criteria derived from a well-referenced research in food allergy, a set of symptoms were used to initially classify the self-reported symptoms as allergic or no allergic reactions. ${ }^{14}$ Participant are considered to have 'allergic reactions' if at least one of the symptoms of skin rashes, swollen eyes, wheeze, difficulty breathing are reported with onsets less than 2 hours after insect ingestion. A secondary classification of allergic reactions was used to further identify those with wheezing, breathing difficulty, hypotension or fainting as 'severe allergic reaction' due to their life-threatening nature. Participants whose answers only included non-specific symptoms, such as headache, dizziness, vomiting, pruritus and diarrhea, were classified as 'no allergic reactions'. Participant are classified as having 'respiratory allergy' if they report history of allergic rhinitis or asthma and 'skin allergy' if history of eczema or urticaria are reported. Participants who specifically reported having allergy to sea fish, prawn, shrimp, lobster, crab, crayfish and mollusks were classified as having 'seafood allergy'.

\section{Statistical analyses}

Descriptive data were presented with frequency, percentage, and mean with standard deviation (SD) and median with interquartile range (IQR) where appropriate. Continuous variables were compared with Student's t-test or Mann-Whitney U test. Associations were tested with chi-square test or Fisher's exact test when appropriated. Prevalence ratio (PR) and 95\% confidence intervals (CI) were estimated. Alpha of 0.05 was used to determine statistical significance.

\section{Results}

From May 1 to October 31, 2017, 140 people responded to the online questionnaire. The range and median (IQR) of age are 18-64 and 27 (23-37) years. Forty-three percent of the respondents were young adult (18-25 years), with $33 \%$ adults (26-39 years), $23 \%$ middle age (40-59 years), and only $1 \%$ elderly ( $\geq 60$ years). Ninety-two $(65.7 \%)$ respondents were female. One hundred and thirty-six respondents (97.1\%) were from Thailand and four were foreigners (two Americans and two Taiwanese). The largest proportion of Thai participants were from Central (48.6\%) and Southern (23.6\%) Thailand. Allergic history were reported in 37 (26.4\%) participants, 
$18.6 \%$ being respiratory allergy, $12.9 \%$ having skin allergy and $2.9 \%$ having eye allergy. Thirteen $(9.3 \%)$ participants reported seafood allergy (Table 1). Ten (7.1\%) participants reported a history of irritable bowel syndrome and none reported inflammatory bowel. Most participants (77.9\%) bought insect products from street vendors or convenient stores (34.2\%). A small proportion $(5.0 \%)$ bought their insects from the markets. Most insect products consumed by participants were from ready-to-eat, roadside stalls $(86.4 \%)$, or as pre-packaged products $(35.7 \%)$. The frequency of insect being consumed, from the highest to lowest, were bamboo caterpillar (71.4\%), silkworm pupa (64.3\%), cricket (48.6\%), grasshopper (45.7\%), giant water bug (17.9\%), spider (2.9\%), scorpion (2.1\%), termite $(2.1 \%)$, dung beetle $(2.1 \%)$, jewel beetle $(0.7 \%)$ and queen ant $(0.7 \%)$. Most participants reported practicing entomophagy out of curiosity and rarely ate it more than once. Only $12.1 \%$ reported consuming insects at least few times a month and $13 \%$ reported eating insect for their nutritional values (Table 2).

Table 1. Characteristics of the participants $(n=140)$

\begin{tabular}{|c|c|}
\hline Characteristics & Values \\
\hline Age (median, IQR) (year) & $27.0(23.0-37.0)$ \\
\hline Gender (female, \%) & $92(65.7)$ \\
\hline \multicolumn{2}{|l|}{ Hometown, Origin (count, \%) } \\
\hline Northern Thailand & $13(9.3)$ \\
\hline Northeastern Thailand & $22(15.7)$ \\
\hline Central Thailand & $68(48.6)$ \\
\hline Southern Thailand & $33(23.6)$ \\
\hline \multicolumn{2}{|l|}{ Others } \\
\hline Taiwan & $2(1.4)$ \\
\hline USA & $2(1.4)$ \\
\hline \multicolumn{2}{|l|}{ Ethnicity (count, \%) } \\
\hline Thai & $135(96.5)$ \\
\hline East Asian & $2(1.4)$ \\
\hline Caucasian & $2(1.4)$ \\
\hline Indian & $1(0.7)$ \\
\hline \multicolumn{2}{|c|}{ Allergic history and other medical history (count, \%) } \\
\hline Allergic history & $37(26.4)$ \\
\hline Skin allergy & $18(12.9)$ \\
\hline Eye allergy & $4(2.9)$ \\
\hline Respiratory allergy & $26(18.6)$ \\
\hline Seafood allergy & $13(9.3)$ \\
\hline Irritable bowel syndrome & $10(7.1)$ \\
\hline Inflammatory bowel disease & 0 \\
\hline
\end{tabular}

Table 2. Insect consumption behaviors among participants $(\mathrm{n}=140)$

\begin{tabular}{|c|c|}
\hline Characteristics & Values \\
\hline \multicolumn{2}{|l|}{ Sources of insects consumed (count, \%) } \\
\hline Market & $7(5.0)$ \\
\hline Convenient store & $48(34.2)$ \\
\hline Street vendor & $109(77.9)$ \\
\hline \multicolumn{2}{|c|}{ Presentation of insect products (count, \%) } \\
\hline Pre-package & $50(35.7)$ \\
\hline Ready-to-eat cooked food & $121(86.4)$ \\
\hline Raw insect for self-cooking & $5(3.6)$ \\
\hline \multicolumn{2}{|l|}{ Types of insects consumed (count, \%) } \\
\hline Bamboo caterpillars & $100(71.4)$ \\
\hline Cricket & $68(48.6)$ \\
\hline Silkworm pupa & $90(64.3)$ \\
\hline Giant water bug & $25(17.9)$ \\
\hline Grasshopper & $64(45.7)$ \\
\hline Scorpion & $3(2.1)$ \\
\hline Spider & $4(2.9)$ \\
\hline Dung beetle & $3(2.1)$ \\
\hline Queen ant & $1(0.7)$ \\
\hline Termite & $3(2.1)$ \\
\hline Jewel beetle & $1(0.7)$ \\
\hline \multicolumn{2}{|c|}{ Reason of insect consumption (count, \%) } \\
\hline Curiosity & $96(68.6)$ \\
\hline Peer influence & $38(27.1)$ \\
\hline Taste & $83(59.3)$ \\
\hline Nutritional values & $13(9.3)$ \\
\hline \multicolumn{2}{|c|}{ Frequency of insect consumption (count, \%) } \\
\hline Regularly (few times a week) & $3(2.1)$ \\
\hline Often (few times a month) & $14(10.0)$ \\
\hline Some times (few times a year) & $43(30.7)$ \\
\hline Rarely, once & $80(57.1)$ \\
\hline
\end{tabular}

Of the 140 participants, $114(81.4 \%)$ reported having no symptom after insect consumption. And while 26 participants reported experiencing symptoms, 18 (12.9\%; 95\%CI 7.3-18.4) had self-reported symptoms that fit the classification for allergic reactions. Of those classified as having allergic reaction, 9 (6.4\%) reported others who consumed insects from the same batch and had reactions as well. As a whole, symptoms being reported were skin rashes and pruritus (10.0\%), wheeze and difficulty breathing $(4.3 \%)$, rhinoconjunctivitis (5.7\%), vomiting $(10.0 \%)$, fainting (1.4\%), headache and dizziness $(12.9 \%)$ 
Table 3. Symptoms after insect consumptions and clinical details $(n=140)$

\begin{tabular}{|c|c|c|c|}
\hline Characteristics & Values & Characteristics & Values \\
\hline Participants with allergic reactions (count, \%) & $18(12.9)$ & Insect associated with the allergic reactions (count, \%) & \\
\hline Symptoms (count, \%) & & Silkworm larva & $8(44.4)$ \\
\hline Skin rashes and pruritus & $14(10.0)$ & Grasshopper & $4(22.2)$ \\
\hline Wheezing or difficulty breathing & $6(4.3)$ & Cricket & $3(16.7)$ \\
\hline Rhinoconjunctivitis & $22(15.7)$ & Bamboo caterpillar & $3(16.7)$ \\
\hline Vomiting & $14(10.0)$ & Duration of symptoms (count, \%) & \\
\hline Fainting & $2(1.4)$ & Less than 1 hour & $2(11.1)$ \\
\hline Headache or dizziness & $18(12.9)$ & 2-3 hours & $6(33.3)$ \\
\hline Hypotension & $2(1.4)$ & Half a day & $4(22.2)$ \\
\hline Cluster of people with allergic symptoms (count, \%) & $9(6.4)$ & One day & $3(16.7)$ \\
\hline Onset of symptoms (count, \%) & & More than one day & $3(16.7)$ \\
\hline Less than 2 hours & $20(14.3)$ & Management for symptoms (count, \%) & \\
\hline 2 to 10 hours & $5(3.6)$ & Self-medication & $8(44.4)$ \\
\hline More than 10 hours & $2(1.4)$ & Sought medical care & $10(55.6)$ \\
\hline Severe symptoms (count, \%) & $4(2.9)$ & Hospitalized & $5(27.8)$ \\
\hline
\end{tabular}

Table 4. Association of variables and allergic reactions after entomophagy $(n=140)$

\begin{tabular}{|c|c|c|c|c|}
\hline Factors & $\begin{array}{l}\text { Allergic symptoms } \\
\qquad(\mathrm{n}=18)\end{array}$ & $\begin{array}{l}\text { No allergic symptoms } \\
\qquad(\mathrm{n}=122)\end{array}$ & PR $(95 \% \mathrm{CI})$ & $p$ value \\
\hline Age (mean (standard deviation)) (year) & $29.1(9.1)$ & $31.5(11.1)$ & - & 0.105 \\
\hline Female (count (\%)) & $11(61.1)$ & $81(66.4)$ & $1.3(0.45-3.5)$ & 0.86 \\
\hline Allergic history (count (\%)) & $11(61.1)$ & $26(21.3)$ & $4.83(1.83-10.44)$ & $0.001^{\star}$ \\
\hline History of respiratory allergy (count (\%)) & $8(44.4)$ & $18(14.8)$ & $3.51(1.54-8.02)$ & $0.007^{*}$ \\
\hline History of skin allergy (count (\%)) & $5(27.8)$ & $13(10.7)$ & $2.61(1.06-6.44)$ & $0.043^{*}$ \\
\hline Seafood allergy (count (\%)) & $5(27.8)$ & $8(6.6)$ & $3.76(1.59-8.87)$ & $0.014^{*}$ \\
\hline Irritable bowel syndrome (count (\%)) & $2(11.1)$ & $8(6.6)$ & $1.62(0.43-6.09)$ & 0.834 \\
\hline
\end{tabular}

$\mathrm{PR}$, prevalence ratio; $\mathrm{CI}$, confidence interval; ${ }^{\star} p<0.05$

and hypotension (1.4\%). And all participants with self-reported allergic reactions experienced these symptoms within 2 hours of ingesting the insects. The types of insects associated with allergic reaction were silkworm pupa, grasshopper, cricket and bamboo caterpillar. Duration of symptoms were mostly half a day or shorter. The majority of people who experienced the allergic symptoms sought medical care with 5 (27.8) being hospitalized (Table 3). Severe allergic reaction were found in 2 participants. Both of them were hospitalized and implicated silkworm pupae, crickets and grasshoppers as being the cause of the symptoms.

Age and gender were not associated with allergic symptoms after insect ingestion. Allergic symptoms after insect consumption were associated with a history of allergy (PR 4.83, 95\%CI $1.83-10.44, p$ value 0.001 ), history of respiratory allergy (PR $3.51,95 \%$ CI $1.54-8.02, p$ value 0.007 ), history of skin allergy
(PR 2.61, 95\%CI 1.06-6.44, $p$ value 0.043 ) and history of seafood allergy (PR 3.76, 95\%CI 1.59-8.87, $p$ value 0.014 ). Association with eye allergy history was not analyzed because the number of cases was small (Table 4).

\section{Discussion}

The population in our study is predominately from Central and Southern Thailand, are relatively young, and carries comparable prevalence of respiratory and skin allergy to those previously reported in predominantly young Thai adults by Uthaisangsook in 2007 and Vichyanond in 2002. ${ }^{15,16}$ The majority of the study population consumes insects sporadically and infrequently, out of curiosity or peer influence.

Prior to our study, the only reported prevalence of insect allergy comes from Barennes et al in the Laos PDR where a randomized national survey is conducted on 1,099 participants 
Table 5. Review of clinical features, allergic and medical history and cluster effects of reported cases of post-entomophagy allergic reactions in English publications

\begin{tabular}{|c|c|c|c|c|c|c|c|}
\hline $\begin{array}{c}\text { Number of cases, } \\
\text { Gender } \\
\text { (age (years)) }\end{array}$ & $\begin{array}{l}\text { Allergic, medical } \\
\text { history }\end{array}$ & Insect & $\begin{array}{l}\text { Symptoms } \\
\text { after ingestion }\end{array}$ & $\begin{array}{l}\text { Onset } \\
\text { (hours) }\end{array}$ & $\begin{array}{l}\text { Cluster, } \\
\text { cluster } \\
\text { size }\end{array}$ & Treatment & Ref. \\
\hline $\begin{array}{l}14 \text { cases, } \\
9 \text { males, } \\
5 \text { famales } \\
(20-54)\end{array}$ & Allergic rhinitis & SP & $\begin{array}{c}\text { A, AP, D, F, FS, } \\
\text { H, HA, P, U, } \\
\text { UC, V }\end{array}$ & $0.5-4$ & No & $\begin{array}{l}\text { HD epinephrine, } \\
\text { IV hexadecadrol, } \\
\text { IM Chlorphenamine, } \\
\text { IV Cetacort }\end{array}$ & 6 \\
\hline $\begin{array}{l}2 \text { cases } \\
2 \text { Males, } \\
(18,44)\end{array}$ & $\begin{array}{l}\text { Latent tuberculosis, } \\
\text { hypertension }\end{array}$ & SP & F, FE, FS, H, U & 1 & Yes, 2 & $\begin{array}{l}\text { AI, IM, IV epinephrine, } \\
\text { IV diphenhydramine }\end{array}$ & 9 \\
\hline $\begin{array}{l}5 \text { Cases } \\
(22-40)\end{array}$ & $\begin{array}{l}\text { Asthma, allergic } \\
\text { rhinitis, urticarial, } \\
\text { food allergy }\end{array}$ & VW & $\mathrm{P}, \mathrm{R}, \mathrm{U}$ & $0.5-2$ & No & No information & 4 \\
\hline $\begin{array}{l}118 \text { cases } \\
(1-70)\end{array}$ & No information & SP & $\begin{array}{c}\text { B, C, CJ, DZ, F, } \\
\text { FE ,FV, MS, N, } \\
\text { NM, P, T, U, }\end{array}$ & $0.25-22$ & Yes, 118 & IV fluid, antihistamines & 7 \\
\hline $\begin{array}{l}27 \text { cases } \\
(13-19)\end{array}$ & None & SP, GH & $\begin{array}{c}\text { BS, D, DR, Dz, } \\
\text { HA, N, NM, } \\
\text { P, V }\end{array}$ & $0.5-7$ & $\begin{array}{c}\text { Yes, } 27 \\
\text { cases }\end{array}$ & $\begin{array}{l}\text { IV chlorpheniramine, domperidone, } \\
\text { nebulized salbutamol }\end{array}$ & 5 \\
\hline
\end{tabular}

A, angioedema; AI, autoinjector; AP, abdominal pain; B, blurred vision; BS, bronchospasm; C, chill; CJ, conjunctivitis; D, dyspnea; DR, diarrhea; DZ, dizziness; F, fainting; FE, facial edema; FS, flushed skin; FV, fever; GH, grasshopper; H, hypotension; HA, headache; HD, hypodermic injection; IM, intramuscular injection; IV, intravenous injection; MS, muscle spasm; N, nausea; NM, numbness; P, pruritus; R, rhinitis; SP, silkworm pupa; T, tremor; U, urticaria; UC, unconsciousness; V, vomiting; VW, vegetable worm

who are insect consumers. In that study, $7.6 \%$ of people who consume insects experience allergic symptoms. ${ }^{1}$ This is slightly smaller than the $12.9 \%$ being reported in our study. The allergic reactions, and in severe cases, anaphylaxis-like symptoms reported by our subjects are very similar to those being reported in the literature (Table 5). ${ }^{4-7,9,17,18} \mathrm{Ji}$ et al in 2008 reported 1 case and reviewed 13 previously reported cases of anaphylaxis after silkworm pupae ingestion. ${ }^{6}$

It is significant that our study also exhibits the same cluster phenomenon seen in other studies elsewhere in the world. ${ }^{5,7,9}$ Symptoms of allergy are reported in a cluster of 2 patients from the USA who have ingested silkworm pupae. ${ }^{9}$ In Thailand, 2 separate patient clusters with severe allergic symptoms after insect ingestion exist, one involving 118 patients who have consumed silkworm pupae and the second involving 27 patients who have consumed silkworm pupae and grasshoppers. ${ }^{5,7}$ Previously, only consumption of silkworm pupae, grasshoppers and vegetable worms have been associated with allergic reactions. ${ }^{4-7,9,17,18}$ The types of insects being reported by this study, namely crickets and bamboo caterpillar, add to the armamentarium of possible insects which can cause allergic reactions.

Currently, there are two mechanisms that may explain the occurrence of allergic symptoms from entomophagy. Type 1 hypersensitivity to the allergen tropomyosin has been proposed in cases where workers develop allergic symptoms after exposure to the allergen in cricket farm or through recreational exposure to pet crickets. ${ }^{10,19,20}$ Tropomyosin is a protein found in shrimp, crustaceans and dust mites and it is reported that these cricket-allergic patients also have hypersensitivity to shrimp, crustaceans and dust mites. ${ }^{19-22}$ This mechanism can help explain the association between pre-existing allergic history and the development of allergic symptoms after entomophagy in our study. However, it does not fully explain why these allergic reactions happen in clusters.

On the other hand, poisoning from histamine contained in the insects can account for the occurrence of mass allergic reactions after consumption of silkworm pupae and grasshoppers. Histamine poisoning, known more widely as scombroid poisoning, is a well-described food-borne illness associated with fish consumption. Histamine, a heat-stable amine, can be produced through bacterial decarboxylation of histidine, an amino acid contained in meaty fish such as tuna. ${ }^{23}$ Insects are postulated to cause histamine poisoning through a similar pathways. ${ }^{5,7}$ In the 2 outbreaks of allergic reactions after consumption of insects in Thailand, toxic histamine concentrations are detected in the implicated insects for both outbreaks. ${ }^{5,7}$ Additionally, in one of the outbreak reported by Chomchai et.al., patients with severe symptoms are reported to have normal serum tryptase concentrations. ${ }^{5}$ In an outbreak reported from the US, allergic reactions among a family members after consumption of the same batch of silkworm pupae are described as having symptoms of "familial anaphylaxis". In particularly, those members who are already sensitive to histamine from their underlying allergic disease may experience more severe symptoms. This serves to further highlight the theory that histamine intolerance, may play a role in the manifestation of allergic reaction in patients exposed to external histamine from food, as is also found in this study. Histamine intolerance is a condition that the body develops symptoms and signs because of imbalance between accumulated histamine and histamine degradation within the body. In one way, histamine intolerance may be an overlapping condition with histamine poisoning. To account for this effect, our questionnaire intentionally include irritable bowel syndrome 
and inflammatory bowel disease in the medical history because these conditions may be associated with histamine intolerance. $^{24}$

There are major limitations in this study. The subject number in our study is small, however this number fulfills the sample size requirements for both the association and prevalence study. The study is conducted using internet-based survey with self-reported allergic symptoms and convenient subject recruitment for feasibility reasons since patients with sicknesses after consumption of insects present sporadically to clinics and emergency departments all over Thailand. Thus, there are no specific institutions where case numbers would be large enough to obtain via a prospective study. The main limitations for such approach are generalizability, reliability and validity of the results. ${ }^{25}$ Generalization of information obtained from internet-based questionnaire survey needs special precaution. People who respond to internet surveys are usually young, with ready access to the internet, are well-educated and are employed. ${ }^{26}$ This is also true for our population. Thus, they represent more of the adventurous foodies who experiment with exotic foods rather than the typical traditional population in rural areas where entomophagy is a way of life. Therefore, these participants may not be representative of the general population who practice entomophagy. Data obtained from internet-based survey can also be associated with inaccuracies. The prevalence rate of a condition or disease obtained through internet-based survey tends to overestimate the true prevalence in the population. Likewise, people who have experienced allergic reactions after insect ingestion may be more likely to participate in the survey, thus leading to over-estimation of the prevalence in this case. ${ }^{27-30}$ Although, the prevalence being reported here is well within range of previously reported number. Over-detection of cases with allergic symptoms may occur due to self-reported allergic symptoms without a confirmatory diagnosis by the physician. ${ }^{31}$ Overall, these factors may result in overestimation of the prevalence of post-entomophagy allergic symptoms. We suggest that prevalence, cluster effects and factors associated with post-entomophagy allergic reactions should be further investigated by studies with larger sample sizes and more objective confirmation of allergic manifestations and risk factors for allergic reactions after insect ingestion.

\section{Conclusion}

Allergic symptoms can be found with a significant prevalence in people who consume insects. People with allergic history, respiratory allergy, skin allergy and seafood allergy have higher risk of developing allergic symptoms from insect ingestion.

\section{Conflict of interest}

The authors declare no conflict of interest.

\section{References}

1. Barennes H, Phimmasane M, Rajaonarivo C. Insect Consumption to Address Undernutrition, a National Survey on the Prevalence of Insect Consumption among Adults and Vendors in Laos. PLoS One. 2015;10: e0136458.
2. Hanboonsong Y, Durst PB, Jamjanya T. Six-legged Livestock: Edible Insect Farming, Collection and Marketing in Thailand. Bangkok: RAP Publication; 2013.

3. van Huis A, Itterbeeck JV, Klunder H, Mertens E, Halloran A, Muir G, et al. Edible insects: future prospects for food and feed security. Rome: Food and Agriculture Organization of the United Nations; 2013. 191 p.

4. Choi GS, Shin YS, Kim JE, Ye YM, Park HS. Five cases of food allergy to vegetable worm (Cordyceps sinensis) showing cross-reactivity with silkworm pupae. Allergy. 2010;65:1196-7.

5. Chomchai S, Chomchai C. Histamine poisoning from insect consumption: an outbreak investigation from Thailand. Clin Toxicol (Phila). 2018;56: 126-31.

6. Ji KM, Zhan ZK, Chen JJ, Liu ZG. Anaphylactic shock caused by silkworm pupa consumption in China. Allergy. 2008;63:1407-8.

7. Mungaomklang A, Teeyapant P, Sangsawang C, Pawun V, Kitphati R, Wuthiwan W, et al. Fried Pupa of Silkworms Food Poisoning Outbreak due to Histamine Toxicity in Seven Provinces-Thailand, Dec 2007 - Jan 2008. Journal of Health Science. 2009;18:504-14.

8. Thanh Nien News [Internet]. Ho Chi Minh City: Vietnam's Youth Association; c2008-2018. Bug eating causes mass poisoning in northern Vietnam; 2014 Jun 20 [cited 2018 Jan 15]; [about 5 screens]. Available from: http://www.thanhniennews.com/health/bug-eating-causes-mass-poison ing-in-northern-vietnam-27409.html

9. Gautreau M, Restuccia M, Senser K, Weisberg SN. Familial Anaphylaxis after Silkworm Ingestion. Prehosp Emerg Care. 2017;21:83-5.

10. Ribeiro JC, Cunha LM, Sousa-Pinto B, Fonseca J. Allergic risks of consuming edible insects: A systematic review. Mol Nutr Food Res. 2018;62. Epub 2017 Jul 31.

11. Chemtrack [Internet]. Bangkok: Chemtrack; c2008-2018. Allergic patients should avoid eating insects; 2008 Apr 3 [cited 2018 Jan 5]; [about 3 screens]. Available from: http://www.chemtrack.org/News-Detail.asp?TID=7\&ID=1 17

12. Department of Medical Sciences [Internet]. Nonthaburi: Department of Medical Sciences; c2013-2018. Department of Medical Sciences alerts allergy patients of hazards from consumption of fried insects; $2013 \mathrm{Oct}$ 14 [cited 2018 Jan 5]; [about 2 screens]. Available from: http://www.dmsc. moph.go.th/dmscnew/news_detail.php?id=59

13. Arya R, Antonisamy B, Kumar S. Sample size estimation in prevalence studies. Indian J Pediatr. 2012;79:1482-8.

14. Kumar R, Caruso DM, Arguelles L, Kim JS, Schroeder A, Rowland B, et al. Early Life Eczema, Food Introduction, and Risk of Food Allergy in Children. Pediatr Allergy Immunol Pulmonol. 2010;23:175-82.

15. Uthaisangsook S. Prevalence of asthma, rhinitis, and eczema in the university population of Phitsanulok, Thailand. Asian Pac J Allergy Immunol. 2007;25:127-32.

16. Vichyanond P, Sunthornchart S, Singhirannusorn V, Ruangrat S, Kaewsomboon S, Visitsunthorn N. Prevalence of asthma, allergic rhinitis and eczema among university students in Bangkok. Respir Med. 2002;96: 34-8.

17. Jirapongsananuruk O, Bunsawansong W, Piyaphanee N, Visitsunthorn N, Thongngarm T, Vichyanond P. Features of patients with anaphylaxis admitted to a university hospital. Ann Allergy Asthma Immunol. 2007;98: 157-62.

18. Piromrat K, Chinratanapisit S, Trathong S. Anaphylaxis in an emergency department: a 2-year study in a tertiary-care hospital. Asian Pac J Allergy Immunol. 2008;26:121-8.

19. Bagenstose AH 3rd, Mathews KP, Homburger HA, Saaveard-Delgado AP. Inhalant allergy due to crickets. J Allergy Clin Immunol. 1980;65:71-4.

20. Linares T, Hernandez D, Bartolome B. Occupational rhinitis and asthma due to crickets. Ann Allergy Asthma Immunol. 2008;100:566-9.

21. Ayuso R, Reese G, Leong-Kee S, Plante M, Lehrer SB. Molecular basis of arthropod cross-reactivity: IgE-binding cross-reactive epitopes of shrimp, house dust mite and cockroach tropomyosins. Int Arch Allergy Immunol. 2002;129:38-48.

22. Broekman H, Knulst AC, de Jong G, Gaspari M, den Hartog Jager CF, Houben GF, et al. Is mealworm or shrimp allergy indicative for food allergy to insects? Mol Nutr Food Res. 2017;61.

23. Colombo FM, Cattaneo P, Confalonieri E, Bernardi C. Histamine food poisonings: A systematic review and meta-analysis. Crit Rev Food Sci Nutr. 2018;58:1131-51.

24. Kovacova-Hanuskova E, Buday T, Gavliakova S, Plevkova J. Histamine, histamine intoxication and intolerance. Allergol Immunopathol (Madr). 2015;43:498-506. 


\section{APJAI}

25. Bahkali S, Almaiman A, Al-Nasser L, Elmetwally A, Househ M. Are Web-based Surveys the New Epidemiological Mode For Healthcare Research? - The Saudi Perspective. Stud Health Technol Inform. 2014;202: $189-92$

26. Im EO, Chee W. Recruitment of research participants through the Internet. Comput Inform Nurs. 2004;22:289-97.

27. Duffy ME. Methodological issues in Web-based research. J Nurs Scholarsh. 2002;34:83-8.

28. Eysenbach G, Wyatt J. Using the Internet for surveys and health research. J Med Internet Res. 2002;4:E13.
29. Mayr A, Gefeller O, Prokosch HU, Pirkl A, Frohlich A, de Zwaan M. Webbased data collection yielded an additional response bias--but had no direct effect on outcome scales. J Clin Epidemiol. 2012;65:970-7.

30. McCabe SE, Couper MP, Cranford JA, Boyd CJ. Comparison of Web and mail surveys for studying secondary consequences associated with substance use: evidence for minimal mode effects. Addict Behav. 2006; 31:162-8.

31. Sicherer SH. Epidemiology of food allergy. J Allergy Clin Immunol. 2011;127:594-602. 